\title{
Patient Waiting Time: Gaps And Determinants Of Patients Waiting Time In Hospitals In Our Communities To Receive Quality Services
}

\author{
S.O. Usman, E. Olowoyeye, O.J. Adegbamigbe, G.P. Olubayo, A.A. Ibijola, \\ A.B. Tijani, I.N. Usman, O.J. Fatunmbi, T.C. Omisakin, and T. Ipinmoye
}

BACKGROUND: Patient waiting time has been recognized as an important indicator for determining the quality of healthcare services offered by health facilities. Waiting time is strongly related to patients' satisfaction with the care received at the hospital in general. METHODS: This is a descriptive crosssectional study carried out in February 2018 among new patients attending general out-patient department (GOPD) of randomly selected hospitals in South-Western Nigeria. A structured pre-tested questionnaire was used to elicit information from 223 patients who were recruited into the study using a convenience sampling method. RESULTS: The average total clinic waiting time (TCWT) from entry to seeing a medical doctor was $137.02 \pm 53.64$ minutes. Only $6(2.7 \%)$ met the Institute of Medicine (IOM) recommendation of having at least $90 \%$ of patients seen within 30 minutes of their scheduled appointment in contrast to $193(86.5 \%)$ of respondents desiring to wait not more than 30 minutes for whatever reason before been attended to by the doctor. Although, the level of satisfaction was high $(81.2 \%)$ in this study, patients who waited longer (>180 min) are more likely to be dissatisfied with services rendered in the OPDs $\left(\chi^{2}=20.104, \mathrm{df}=1, \mathrm{P}=\mathbf{0 . 0 0 1}\right)$. Factors such as few health personnel $(81 / 120)$ and having an insurance cover contributed significantly to the waiting time $\left(\chi^{2}=19.54, \mathrm{df}=1\right.$, $P=0.001)$. CONCLUSION: In a competitively managed health care environment, patient waiting time play an increasingly important role in a clinic's ability to attract new business. Efforts therefore, should be made not only to reduce the patient waiting time, but health managers should invest in resources and activities that ensure a productive use of the time patients spend in the process of seeking healthcare services.

Keywords - Patient; waiting time; determinants; hospital

\section{INTRODUCTION}

Patient waiting time is defined as the length of time patients wait before being seen by a clinic medical staff [1]. It has been recognized as an important indicator for determining the quality of healthcare services offered by health facilities. Several studies have established a strong link between waiting time with patients' satisfaction [2, 3, 4 \& 5]. Generally, the patient waiting time varies across settings. In a Nigerian study published in $2013,61 \%$ of the respondents waited for $90-180$ minutes in the clinic, whereas $36.1 \%$ of the patients spent less than 5 minutes with the doctor in the consulting room. The commonest reason for the long waiting time in the GOPD was the large number of patients with few healthcare workers [6]. Also, $31 \%$ of the patients waited for less than an hour in the waiting room in a 2011 research work, which revealed as well that $96.6 \%$ spent less than 30 minutes with the doctor while more than half $(55 \%)$ were satisfied with the service delivery in the hospital and $16 \%$ of the respondents admitted to being given health talks while waiting to be seen by the doctor [7]. In Vietnam, the average waiting time from registration to preliminary diagnosis in 2014 was 50.41 minutes and in 2015 was 42.05 minutes. A longer waiting time was recorded in the morning and in those having health insurance. In Northern Ethiopia, the overall patient satisfaction in health care services rendered at Deherebirhan referral hospital was $57.7 \%$. Majority of the patients were satisfied with the quality of medical instruments $(88.9 \%)$. Older age, provision of prescribed drugs, higher educational status and those who were not charged for service, were significantly associated with patient satisfaction [3]. In North West Ethiopia, the mean waiting time was 149.2 minutes in a particular referral hospital while it was 94.2 minutes in another. The major causes of long patient waiting time was large numbers of patients with a few doctors $(40.5 \%$ and $28.9 \%$ in both hospitals respectively) and long registration time (25.4\% and $32.5 \%$ respectively) [2].This study aimed at assessing the patient waiting time and factors responsible for the waiting time at the general outpatient department (GOPD) of two high-volume patient hospitals in Southwestern Nigeria.

\section{AIM \& OBJECTIVES OF THE STUDY}

The aim of the study is to determine the patient waiting time and its determinants in the General Out-Patient Department in this setting.

Objectives:

- To determine the total clinic waiting time (TCWT) in this setting.

- To identify the determinants of clinic waiting time (TCWT) in this setting. 


\section{METHODS}

This was a cross sectional study done at the General Out Patient Department (GOPD) of selected public \& private hospitals in Ekiti State, South-Western Nigeria. A structured questionnaire and waiting time assessment card were used to elicit information on socio-demographic characteristics of largely adult patients (14 years and above) with the exclusion of pregnant women, time spent before registration, time spent in the waiting area, and time spent to see the doctor, laboratory scientist, pharmacist and other health care workers as well as level of satisfaction with services rendered in the hospitals. Trained research assistants helped respondents who could not easily comprehend the questionnaire completion. A stop watch was used to record the time spent in the waiting room and time spent with the doctor in the consultation room, at the laboratory as well as at the pharmacy.

The questionnaire was pretested at the GOPD of a specialist hospital located some distance from the hospital. Only new patients presenting to the GOPD for the first time and who gave their consent to participate in the study were selected while critically ill patients were excluded from the study. Ethical approval to carry out the study was obtained from the ethical review committee of the Federal Teaching Hospital, Ido-Ekiti.

A total of 233 consenting patients were recruited into the study using a systematic sampling technique after calculating the sample interval $(\mathrm{k})$ :

Sample interval $(\mathrm{k})=$ Average number of targeted population/Minimum required sample size $=300 / 210=1.43$. This was approximated to 2 .

Based on the sampling interval, the systematic sampling technique was carried out as follows;

1. Simple random sampling was done for the first two patients to get the starting point.

2. Thereafter, every other new patient that came to the clinic was enrolled in the study over a two day period until the required sample size was obtained.

\section{Sample Size Estimation}

The minimum sample size determined using the formula for estimating required sample size in a population less than $10,000[9]$.

$\mathrm{N}_{\mathrm{f}}=\mathrm{n} / 1+(\mathrm{n} / \mathrm{N})$

$\mathrm{n}=\mathrm{Z}_{2} \mathrm{pq} / \mathrm{d}_{2}$ where $\mathrm{n}=$ sample size, $\mathrm{Z}=$ standard normal

deviation at $95 \% \mathrm{CI}=1.96$

$\mathrm{p}=$ prevalence of the factor under consideration; $84 \%(0.84)$

from a previous study [10].

$\mathrm{q}=$ Complementary factor $(1-\mathrm{p})=0.16$

$\mathrm{N}=$ Average number of targeted population (i.e. average number of patients attending GOPD daily) $=300$ (50 for the private and 250 for the public hospital)

$\mathrm{N}_{\mathrm{f}}=$ Minimum required sample size for population less than 10,000 .

$\mathrm{n}=1.962 \times 0.84 \times 0.16=206.52$

$$
0.052
$$

$\mathrm{N}_{\mathrm{f}}=(206.52 / 1+206.52 / 300) \simeq 210$

Also, adding a $5 \%$ non-response rate, the minimum sample size $(\mathrm{n})=5 / 100 \times 210=11$

Thus, $11+210=221=n$

The sample size was then distributed between the two hospitals in ratio $1: 5$

Private $=1 / 6 * 210=35$ and public $=5 / 6 * 210=175$

\section{STATISTICAL ANALYSIS}

Data was statistically analyzed using Statistical Package for the Social Sciences (SPSS) for windows version 23.0 software (SPSS Inc., Chicago, IL, USA). Data were expressed as Mean \pm Standard Deviation (SD). Frequency counts were generated for all variables and statistical test of significance was performed with Chi-Square test. Significance was fixed $\mathrm{P}<0.05$ and highly significance when $\mathrm{P}<0.01$.

\section{RESULTS}

\section{SOCIO-DEMOGRAPHIC DATA}

A total of 223 respondents participated in the study. The mean age $\pm \mathrm{SD}$ is $37.94 \pm 15.47$ years. $142(63.7 \%)$ of the respondents are females while $81(36.3 \%)$ were males. Most of them are married 157 (70.4\%), of Yoruba ethnic group 202 (90.6\%), Christians $159(71.3 \%)$ and with a formal education $214(96.0 \%)$. Majority $183(82.1 \%)$ of the respondents visited public owned facility while $40(17.9 \%)$ visited private hospital. There were on the average more than 100 patients attending OPD within the study period.

TABLE I - Socio-demographic data of respondents $(\mathrm{n}=223)$

\begin{tabular}{|c|c|}
\hline Variables & Frequency $(\%)$ \\
\hline \multicolumn{2}{|l|}{ Age Group (years) } \\
\hline $14-25$ & $55(24.7)$ \\
\hline $26-35$ & $61(27.4)$ \\
\hline $36-45$ & $50(22.4)$ \\
\hline $46-55$ & $28(12.6)$ \\
\hline$>55$ & $29(13.0)$ \\
\hline \multicolumn{2}{|l|}{ Gender } \\
\hline Male & $81(36.3)$ \\
\hline Female & $142(63.7)$ \\
\hline \multicolumn{2}{|l|}{ Marital Status } \\
\hline Single & $60(26.9)$ \\
\hline Married & $157(70.4)$ \\
\hline Cohabitating & $1(0.4)$ \\
\hline Separated & $1(0.4)$ \\
\hline Widowed & $4(1.8)$ \\
\hline \multicolumn{2}{|l|}{ Religion } \\
\hline Christianity & $159(71.3)$ \\
\hline Islamic & $6227.8)$ \\
\hline Traditional & $2(0.9)$ \\
\hline \multicolumn{2}{|l|}{ Tribe } \\
\hline Hausa & $5(2.2)$ \\
\hline Igbo & $16(7.2)$ \\
\hline Yoruba & $202(90.6)$ \\
\hline \multicolumn{2}{|l|}{ Level of Education } \\
\hline No formal Education & $9(4.0)$ \\
\hline Primary Education & $18(8.1)$ \\
\hline Secondary Education & $59(26.5)$ \\
\hline Tertiary Education & $137(61.7)$ \\
\hline \multicolumn{2}{|l|}{ Occupation } \\
\hline Artisan & $26(11.7)$ \\
\hline Trader/Small Business & $50(22.4)$ \\
\hline Public Servant & $65(29.1)$ \\
\hline Technician & $12(5.4)$ \\
\hline Teacher & $9(4.0)$ \\
\hline Unemployed & $5(2.2)$ \\
\hline Self employed & $19(8.5)$ \\
\hline Private sector worker & $10(4.5)$ \\
\hline Student & $26(11.7)$ \\
\hline
\end{tabular}

TABLE 2 - Patient volume and Hospital Distribution $(\mathrm{n}=223)$

\begin{tabular}{|l|l|}
\hline Variables & Frequency (\%) \\
\hline Class of Hospital & $40(17.9)$ \\
\hline Private & $183(82.1)$ \\
Public Primary & \\
\hline Patient Volume & \\
\hline
\end{tabular}




\begin{tabular}{|l|l|}
\hline $20-39$ & $2(0.9)$ \\
$40-59$ & $4(1.7)$ \\
$60-79$ & $17(7.6)$ \\
$80-99$ & $76(34.1)$ \\
$100 \&$ above & $97(43.5)$ \\
Can't say & $27(12.1)$ \\
\hline Total & $\mathbf{2 2 3}(\mathbf{1 0 0 . 0})$ \\
\hline
\end{tabular}

TABLE 3: Patients' satisfaction and determinants $(\mathrm{n}=223)$

\begin{tabular}{|c|c|}
\hline Variables & Frequency $(\%)$ \\
\hline \multicolumn{2}{|l|}{ Opinion about waiting time } \\
\hline Short & $7(3.1)$ \\
\hline Just right & $96(43.1)$ \\
\hline Too long & $120(53.8)$ \\
\hline \multicolumn{2}{|c|}{ Factors responsible for long waiting time $(n=120)$} \\
\hline Few health personnel & $81(67.5)$ \\
\hline Staff taking too long & $25(20.8)$ \\
\hline Staff poor attitude & $12(10.0)$ \\
\hline Staff member/patients jumping queue & $2(1.7)$ \\
\hline \multicolumn{2}{|l|}{ Pre-occupation during waiting period } \\
\hline Watching television & $83(37.2)$ \\
\hline Simply sitting/Watching happenings in the & $96(43.0)$ \\
\hline clinic & $17(7.6)$ \\
\hline Reading Newspaper/Magazine & $7(3.1)$ \\
\hline Listening to health talk & $10(4.5)$ \\
\hline Busy with phone & $2(0.9)$ \\
\hline $\begin{array}{l}\text { Reading religious book/praying } \\
\text { Others }\end{array}$ & $8(3.6)$ \\
\hline \multicolumn{2}{|l|}{ Time of visit } \\
\hline Morning & $186(83.4)$ \\
\hline Afternoon & $34(15.2)$ \\
\hline Evening & $3 \quad(1.3)$ \\
\hline \multicolumn{2}{|l|}{ Are you satisfied? } \\
\hline Yes & $181(81.2)$ \\
\hline No & $42(18.8)$ \\
\hline \multicolumn{2}{|l|}{ Would you recommend the hospital? } \\
\hline Yes & $208(93.3)$ \\
\hline No & $13(5.8)$ \\
\hline No response & $2(0.9)$ \\
\hline \multicolumn{2}{|l|}{ If no, why? (n=15) } \\
\hline Long waiting time & $6(40.0)$ \\
\hline Poor staff attitude to work & $5(33.3)$ \\
\hline Few health personnel & $4(26.7)$ \\
\hline \multicolumn{2}{|l|}{ Are you on any insurance scheme? } \\
\hline Yes & $115(48.4)$ \\
\hline No & $108(51.6)$ \\
\hline \multicolumn{2}{|l|}{ Did you receive any free service in any unit? } \\
\hline Yes & $86(38.6)$ \\
\hline No & $137(61.4)$ \\
\hline
\end{tabular}

\section{DISCUSSION}

In this study, the average total clinic waiting time (TCWT) from entry to seeing a medical doctor was $137.02 \pm 53.64$ minutes. Overall, $185(83.0 \%)$ waited for less than 180 minutes while $38(17.0 \%)$ waited for more than 180 minutes before seeing a medical doctor. Only $6(2.7 \%)$ met the Institute of Medicine (IOM) recommendation of having at least $90 \%$ of patients seen within 30 minutes of their scheduled appointment [11]. 76 (34.1\%) waited between 4 to 89 minutes before being registered while 147 (65.9\%) waited for 90 minutes and above to be registered. Regarding consultation, 77 (34.5\%) spent a maximum of 10 minutes in the consultation room with the doctor. In contrast, 193 $(86.5 \%)$ of the respondents desire to wait not more than 30 minutes for whatever reason before been attended to by the doctor. This finding is slightly lower than that of some studies in the Northern Nigeria which reported a TCWT of $168 \pm 35$ minutes [6] and median patient clinic encounter time of 162 minutes [12]. It was also remarkably lower than the average $181 \pm 34.8$ minutes reported in Abeokuta South West Nigeria [5] whereas, it is almost similar to that reported in a referral hospital in North West Ethiopia [2]. This further speaks to the variability of TWCT in different settings. Similarly, majority (78\%) of the subjects in a study were of the opinion that, the ideal waiting time should not be longer than $30 \mathrm{~min}$ from the time of arrival in the hospital to the time the patient is attended to by the doctor [7].

There were 2 record officers, 3 nurses, 3 Doctors, 3 Laboratory staff and 3 pharmacy staff respectively available in the hospital during this study period. $7(3.1 \%)$ of the respondents felt that the time spent was short, 96 (43.1\%) felt that it was just right while $120(53.8 \%)$ opined that the waiting time was too long. Factors linked with long waiting time were few health personnel (81/120), staff taking too long with a patient (25/120), poor attitude of staff such as lateness $(12 / 120)$ as well as staff member or patients jumping the queue $(2 / 120)$. This is in line with those findings of Oche and Adamu where availability of few doctors in the clinic to attend the numerous patients, few fling and record clerks as well as jumping of queue by patients or staff members accounted for the reported long waiting time [6].

In this study, only 7 (3.1\%) of the patients admitted to being given health education while $37.2 \%$ watched television and the majority 96 (43.0\%) simply sat or watched happenings in the OPDs. Most of the respondents, $186(83.4 \%)$ visited the clinic in the morning, followed by $34(15.2 \%)$ in the afternoon and $3(1.3 \%)$ in the evening. The attending boredom by simply sitting in the clinic especially in the morning which is assumed to be the most productive time of the day before seeing the clinical staff can always be minimized if patients are engaged in interesting activities. This finding is in consonance with that in Ibadan, where it was observed that, the three common activities patients engaged in during waiting time were watching happenings in the clinics, reading and chatting [13]. Some study participants however preferred health education specific health issues as a constructive way of utilizing their time while waiting in the OPDs as reported in Ibadan [13] and Saudi Arabia [14].

We also reported the time it took patient to be seen by the laboratory and pharmacy unit. In addition to the preconsultation and consultation time, the average TCWT increased to $176.81 \pm 77.55$ minutes. However, majority of the respondents, $181(81.2 \%)$ were satisfied with the services provided while $42(18.8 \%)$ were not. Also, 208 (93.3\%) are willing to recommend the hospital to others. Recent studies also showed an increase in patient satisfaction with healthcare services $[4,5]$. This is not surprising because health managers are increasingly recognizing the patients as a major drive in shaping the competitions in the health sector. Another reason could be the preference of patients to utilize tertiary hospitals in this setting because they anticipate better services. Long waiting time was the most common reason (6/15) why patients were not willing to recommend healthcare services while poor staff attitude to work and few health personnel accounted for $5 / 15$ and $4 / 15$ respectively. Long waiting time before registration has been adjudged as a major contributory factor to the total waiting time in various setting as observed in this study [4, 6, $7 \& 15]$. This could be as a result of shortage of manpower evidenced by two record clerks attending to an average of 100 new patients daily in addition to a far greater number of follow up attendants. 


\section{CONCLUSION}

In a competitively managed health care environment, patient waiting time play an increasingly important role in a clinic's ability to attract new business. Efforts therefore, should be made not only to reduce the patient waiting time while seeking healthcare services.

\section{ACKNOWLEDGEMENTS}

Our sincere appreciation goes to all participants that took part in this study.

\section{FINANCIAL \& NON-FINANCIAL COMPETING INTEREST}

The authors declare no financial or non-financial competing interest.

\section{CONFLICT OF INTEREST}

Authors declare they have no conflict of interest.

\section{REFERENCES}

[1] C.E. Rossiter \& F.A. Raynolds (1968). Automatic monitoring of the time waited in an outpatient clinic. Journal Storage: Med Care,1: $218-25$.

[2] M. Belayneh, M. Woldie, N. Berhanus \& M. Taminu (2017). The determinants of patient waiting time in the general outpatient department of Debie Markos and Feleye Hiwot Hospitals in Amhara regional state, North West Ethiopia, Global Journal of Medicine and public Health, 6 (5): $1-17$.

[3] R. Mezemir, D. Getachew \& M. Gebreslassie (2014). Patients' Satisfaction and its determinants in Outpatient Department of Deberebirhan Referral Hospital, North Shoa, Ethiopia. International Journal of Economics \& Management Science, 3:191. doi:10.4172/2162-6359.1000191.

[4] O.J. Daniel (2013). Patient Satisfaction with Health Services at the Out-patient Department of A Tertiary Hospital In Nigeria. Nigerian Journal of Clinical Medicine, 5(1): 17-22.

[5] P.O. Onifade, E.B. Somoye \& T.A. Adamson (2010). Wait Time and Service Satisfaction at the Outpatient Clinic of a Nigerian Psychiatric Hospital. Nigerian Journal of Psychiatry, 8(2): 20-26.

[6] M.O. Oche \& H. Adamu (2013). Determinants of patient waiting time in the general outpatient department of a tertiary institution in North western Nigeria. Annals of Medical \& Health Science Research, 3 (4): $588-592$.

[7] I. Umar, M.O. Oche \& A.S. Umar (2011). Patient waiting time in a tertiary health institution in northern Nigeria. Journal of Public health \& Epidemiology, 3(2): 78-82.

[8] T.D. Tran, U.V. Nguywn, U.M. Nong \& B.X. Tran (2017). Patient waiting time in the outpatient clinic at a central surgical hospital of Vietnam: Implications for resource allocation. F1000 Research, 6: 454.

[9] M.A. Araoye (2003). Sample size determination. In: Research methodology with statistics for health and social sciences. 1st ed. Illorin: Nathadex Publishers, p. 115-21.

[10] A.N. Oflli \& C.E. Ofowve (2005). Patient's assessment of effciency of services at a teaching hospital in a developing country. Annals of African Medicine, 4:150-3.

[11] M.S. O’Malley, S.W. Fletcher, R.H. Fletcher \& J.A. Earp. Measuring patient waiting time in a practice setting: A comparison of methods. The Journal of Ambulatory Care Management 1983;6:20-7.

[12] O. Ogunfowokan \& M. Mora (2012). Time expectation and satisfaction: Patient experience at National Hospital Abuja, Nigeria. African Journal of Primary Health Care \& Family Medicine, 4(1), Art. 398, 106-109.
[13] I.O. Ajayi, E.A. Olumide \& O. Oyediran (2005). Patient satisfaction with the services provided at a General Outpatients' Clinic, Ibadan, Oyo State, Nigeria. African Journal of Medical \& Health Science, 34(2):133-140.

[14] E. Bamgboye \& J. Jarallah (1994). Long waiting Outpatients: Target Audience for Health Education. Patient Education \& Counselling, 23: 49-54.

[15] C.B. O’Neill, M.E. Edim \& B.O. Obarein (2014). Causes of Prolonged Waiting Time in Public Health Facilities among Health Care Seekers in Calabar Municipal Council of Cross River State, Nigeria. Research on Humanities and Social Science, 4(20):122-27.

[16] K.S. Prasanna, M.A. Bashith \& S. Sucharitha (2009). Consumer satisfaction about Hospital services: A study from the Outpatient department of a Private Medical College Hospital at Mangalore. Indian Journal of Community Medicine, 34( 2): 156-159.

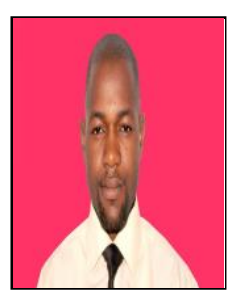

Saheed Usman is an efficient \& resourceful award winning health professional, researcher \& scholar with over ten years' experience in laboratory medicine \& public health intervention programs implementation health system strengthening programs for control of infectious and noncommunicable diseases. $\mathrm{He}$ has several publications in reputable local \& international journals, presentations at various clinical \& laboratory conferences \& congresses, with travel grants \& scholarships from various international organizations. Currently, Saheed is a Technical Officer at APIN Public Health Initiatives, Abuja, Nigeria. 